\title{
Ibrutinib-Associated Nail Plate Abnormalities: Case Reports and Review
}

\author{
Lucas A. Heldt Manica ${ }^{1}$ Philip R. Cohen ${ }^{2}$
}

Published online: 1 November 2017

(c) The Author(s) 2017. This article is an open access publication

\begin{abstract}
Chronic lymphocytic leukemia is a lymphoproliferative disorder characterized by a gradual accumulation of neoplastic B-lymphocytes. Ibrutinib is a novel therapy for chronic lymphocytic leukemia. Ibrutinib therapy has been associated with nail plate abnormalities. Other common cutaneous adverse events caused by ibrutinib appear to be bruising, hair changes, pruritus, and rashes. We describe the clinical features of two patients with chronic lymphocytic leukemia: a 79-year-old woman and a 53-year-old man who developed nail plate abnormalities approximately 6 and 4 months, respectively, after beginning ibrutinib therapy. We also review the characteristics of other patients with chronic lymphocytic leukemia with ibrutinib-associated nail plate abnormalities. The PubMed database was used to search the following terms: abnormal, abnormalities, adverse, brittle, chronic, cutaneous, dystrophy, events, effects, ibrutinib, lymphocytic, leukemia, nail, plate, and side. The relevant referenced papers generated by the search were reviewed. In conclusion, ibrutinib is used to treat chronic lymphocytic leukemia. It is usually
\end{abstract}

Lucas A. Heldt Manica

manica@ hawaii.edu

Philip R. Cohen

mitehead@gmail.com

1 John A. Burns School of Medicine, University of Hawaii, 5737 Kalanianaole hwy, Honolulu, HI 96821-1741, USA

2 Department of Dermatology, University of California San Diego, La Jolla, 10991 Twinleaf Court, San Diego, CA 92131-3643, USA well-tolerated. Many patients receiving ibrutinib will develop nail plate abnormalities. This adverse event is not a drug-limiting toxicity.

\section{Key points}

Ibrutinib, a tyrosine kinase inhibitor, is a novel therapy for chronic lymphocytic leukemia that has been associated with nail plate abnormalities.

The brittle nails in ibrutinib-treated patients may result from the drug's ability to disrupt the disulfide bonds between the cysteine residues in the nail.

The ibrutinib-associated nail changes that occur in patients with chronic lymphocytic leukemia are not a drug-limiting toxicity.

\section{Introduction}

Chronic lymphocytic leukemia is a lymphoproliferative disorder characterized by a gradual accumulation of neoplastic B-lymphocytes. Ibrutinib, a tyrosine kinase inhibitor, is a novel therapy for chronic lymphocytic leukemia; it is typically dosed at $420 \mathrm{mg}$ orally once daily. Tyrosine kinase is a cytoplasmic enzyme that is essential for B-lymphocyte survival; it is involved in the regulation of trafficking, homing and adhesion of chronic lymphocytic leukemia cells [1-4]. We describe two patients with chronic lymphocytic leukemia who developed nail plate abnormalities after initiating therapy with ibrutinib. 


\section{Case Reports}

\section{Case 1}

A 79-year-old woman with chronic lymphocytic leukemia was referred by her oncologist for a skin check. The patient noted changes in the appearance and texture of her nails within 6 months of starting systemic treatment for chronic lymphocytic leukemia with ibrutinib at an oral daily dose of $420 \mathrm{mg}$. She was not receiving any other chronic lymphocytic leukemia-directed therapy.

Cutaneous skin examination was significant for changes of her toenails (Figs. 1, 2, 3) and fingernails, which appeared fragile and brittle; biotin $2.5 \mathrm{mg}$ daily was prescribed. In addition, she had ecchymoses on her arms and legs. Ten actinic keratosis were discovered and treated with cryotherapy. No cutaneous malignancies were diagnosed.

At follow-up evaluation 3 months after starting biotin, her toenails were less brittle. New ecchymoses on her extremities continued to develop.

\section{Case 2}

A 53-year-old man with chronic lymphocytic leukemia was referred by his oncologist for a skin check. The patient noted that the appearance of his nails had changed within 4 months of starting systemic treatment for chronic lymphocytic leukemia with ibrutinib at an oral daily dose of 420 mg. ABT199 (Venetoclax), a Bcl-2 inhibitor, had been added 3 months after the initiation of ibrutinib. He was not receiving any other chronic lymphocytic leukemia-directed therapy.

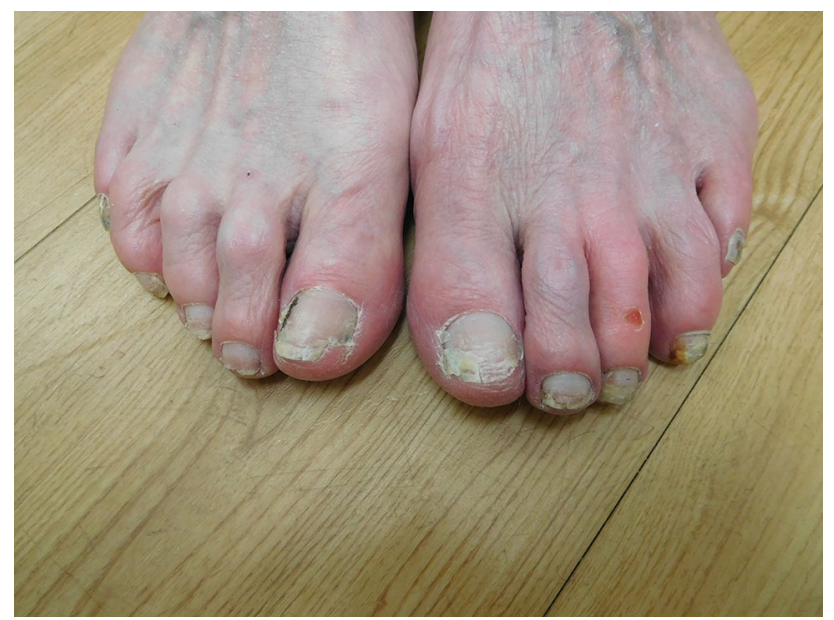

Fig. 1 Distant view of ibrutinib-induced nail changes on the toes of a 79 -year-old woman with chronic lymphocytic leukemia. The toenails are fragile and brittle. There is distal shedding of the right great toenail and horizontal splitting of the left great toenail. Drugassociated erosion of the distal left third toe is also present

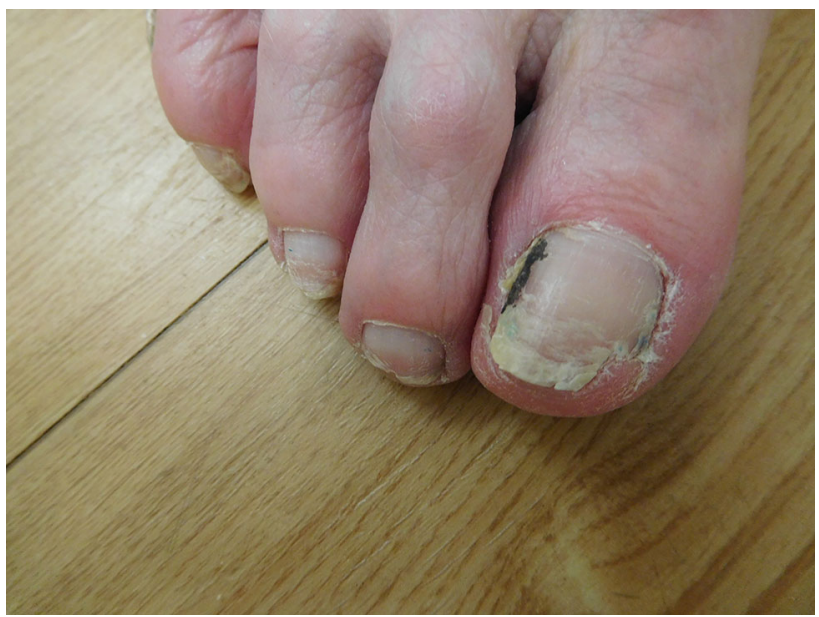

Fig. 2 A closer view of the toenail changes on the right foot of a 79-year-old woman receiving daily ibrutinib treatment for chronic lymphocytic leukemia. The lateral nailfold of the great toe shows a linear black streak of nail polish. Trachyonychia of the nails is present; the distal nail of the great toe and second toe are partially shed

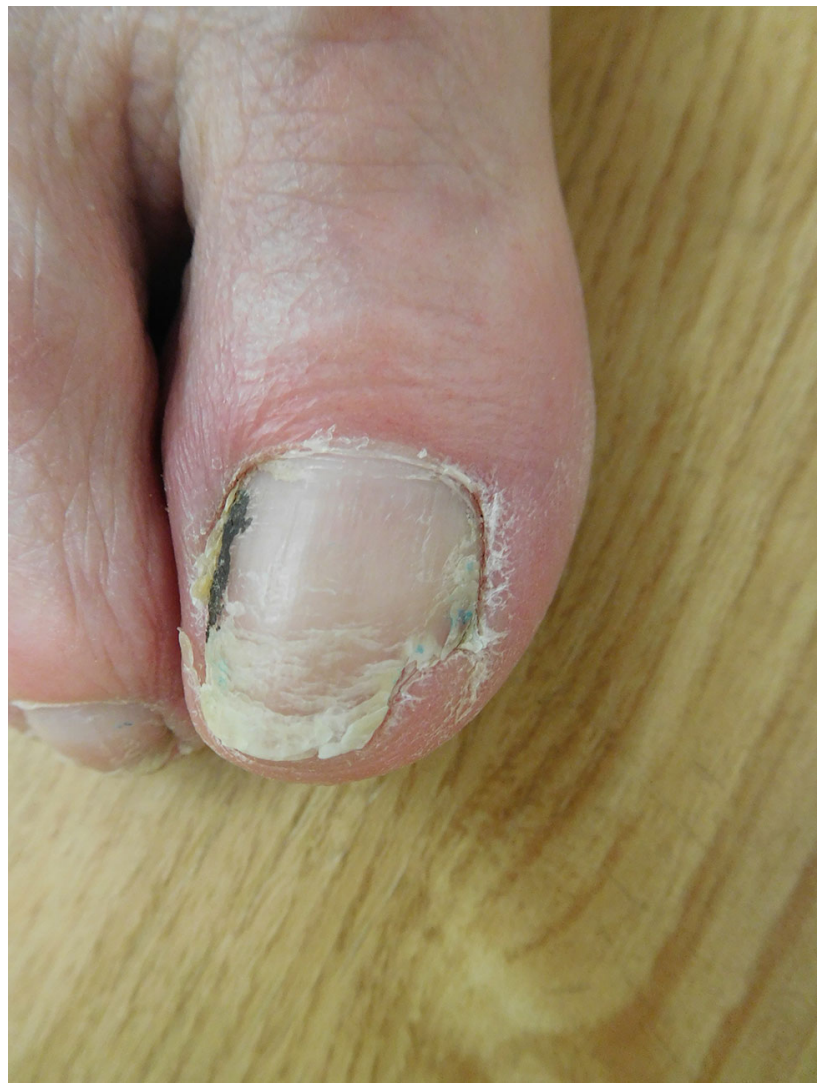

Fig. 3 Ibrutinib-associated changes of the distal right great toe and toenail in a woman with chronic lymphocytic leukemia. There is erythema of the proximal nailfold. The surface of the nail is rough and there are horizontal ridges. The distal nail shows fissures and splitting; the lateral portion has shed 
Cutaneous skin examination was significant for changes to the nails on his thumb (Fig. 4), finger (Figs. 5 and 6) and toe (Fig. 7); they appeared fragile and brittle. Biotin $2.5 \mathrm{mg}$ daily was prescribed. In addition, desquamative dermatitis with red-brown macules and petechiae was present on the tip of the left great toe (Fig. 8). No cutaneous malignancies were observed.

\section{Discussion}

Chronic lymphocytic leukemia is hematologic malignancy of B-lymphocytes. It is one of the most common leukemias diagnosed in adults [1,5-7]. It primarily presents in older individuals; $70 \%$ of patients are aged $>65$ years at the time of diagnosis [1, 5-7].

A diagnosis of chronic lymphocytic leukemia should be considered in the presence of unexplained absolute or relative lymphocytosis [1,5-7]. The clinical course of chronic lymphocytic leukemia is variable. In some patients, the disease can progress rapidly and lead to death a few years after diagnosis [7, 8], whereas in other patients the disease has an indolent course and the patients may never need treatment $[7,8]$.

The first-line treatment for patients with chronic lymphocytic leukemia often includes a combination of chemotherapy agents and immunotherapy (anti-CD20 monoclonal antibody) $[1-3,5-7,9,10]$. However, the age and comorbidities of the individuals being treated often limit the applicability of these standard treatments. $[1,2,5-7,11]$. Ibrutinib is a new drug for the treatment of patients with chronic lymphocytic leukemia.

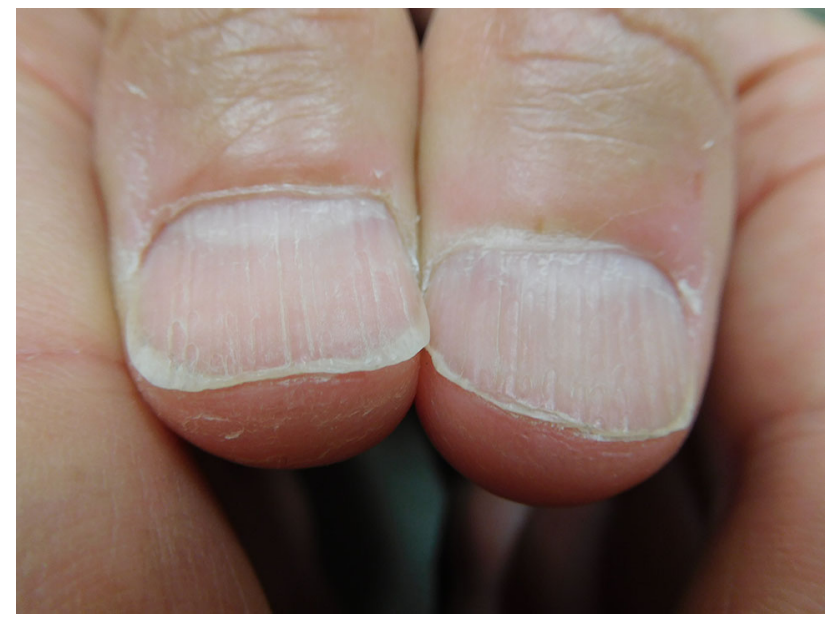

Fig. 4 Ibrutinib-induced nail changes in a 53-year-old man with chronic lymphocytic leukemia. There are longitudinal ridges. There is longitudinal and horizontal splitting of the nail. Distal shedding of the nail is also present. In addition, there is dermatitis of the tips of the thumbs with superficial desquamation

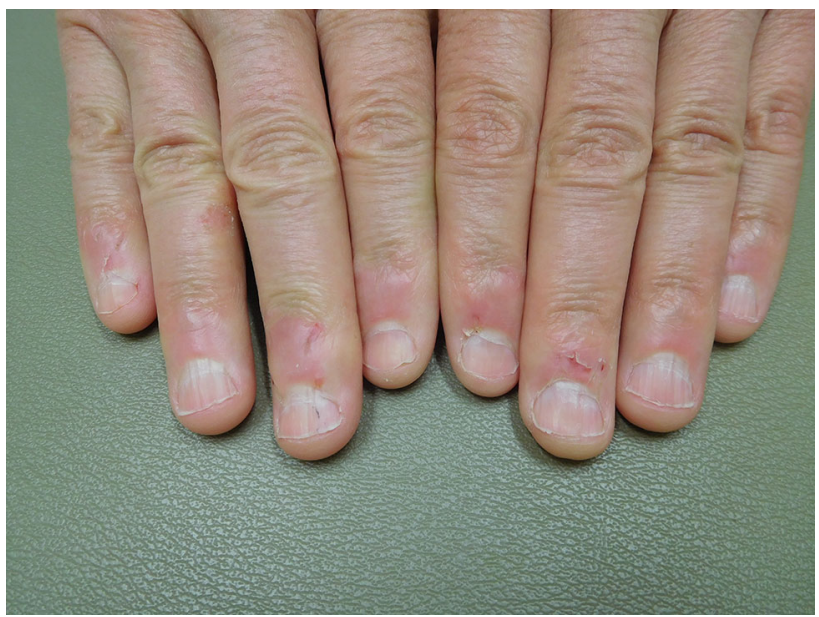

Fig. 5 Distant view of ibrutinib-associated fingernail changes in a 53-year-old man with chronic lymphocytic leukemia. The thin fingernails are fragile and brittle. Drug-induced dermatitis is affecting the distal fingers, including the proximal nailfolds

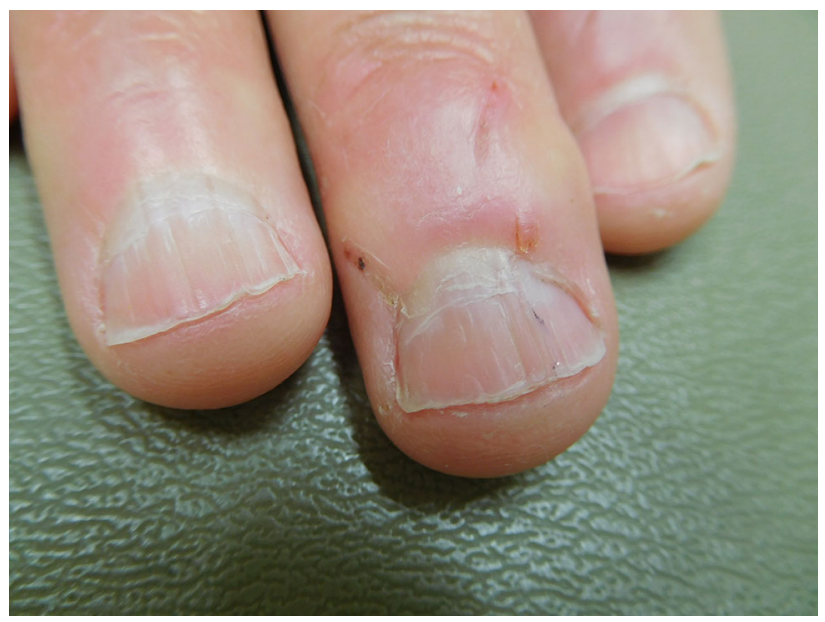

Fig. 6 Close view of the distal fingers of a man with chronic lymphocytic leukemia who is being treated with ibrutinib. There is trachyonychia with linear splitting of the nail; there is also horizontal splitting and shedding of the distal nail. A splinter hemorrhage is present on the middle fingernail. Talon noir, blood in the stratum corium, can be seen in the lateral nailfold of the middle finger

Ibrutinib is an oral, irreversible tyrosine kinase inhibitor. It affects neoplastic cells by covalently binding in the cysteine moiety in the active site of tyrosine kinase, resulting in subsequent inhibition of neoplastic cell proliferation, substrate adhesion, migration and survival $[1,3,4]$.

Ibrutinib is generally well tolerated. Significant side effects of the medication include anemia, atrial fibrillation, bleeding, diarrhea, fatigue, fever, hypertension, muscle and bone pain, nausea, neutropenia, pneumonia, thrombocytopenia and tumor lysis syndrome [1-6, 10, 12]. Bruising, hair changes and nail plate abnormalities, pruritus and rashes are the most common cutaneous side effects of 


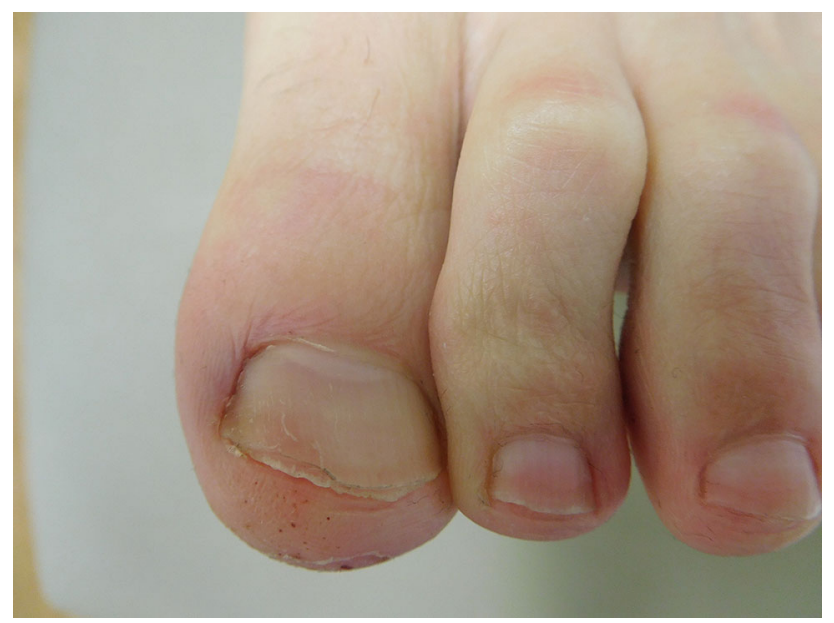

Fig. 7 The left great toenail of a 53-year-old man with chronic lymphocytic leukemia who is being treated with ibrutinib. There is koilonychia. The nail is fragile and brittle; there is horizontal splitting and shedding of the distal nail

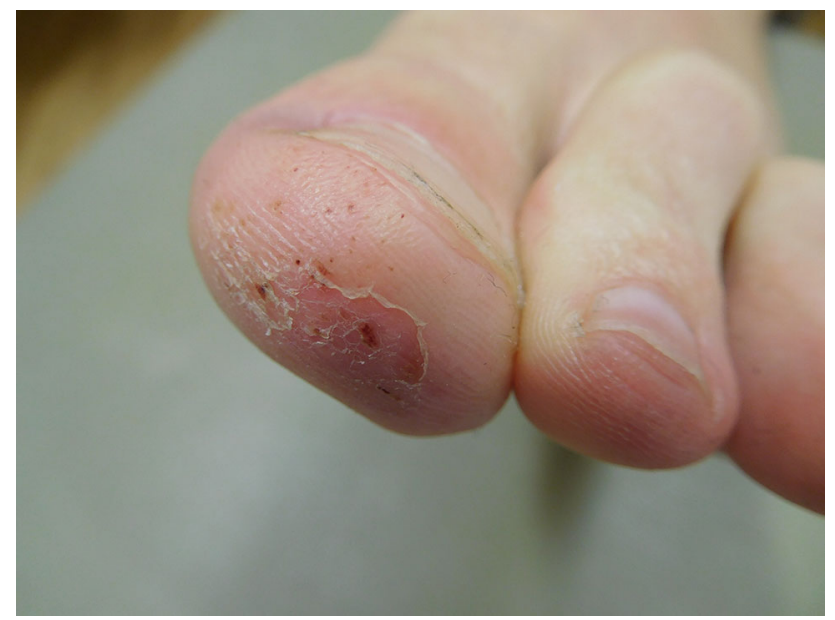

Fig. 8 The distal left great toenail of a 53-year-old man with chronic lymphocytic leukemia. The tip of the toe shows ibrutinib-induced dermatitis presenting as superficial desquamation. There is also hemorrhage in the superficial epidermis presenting as red-brown macules and petechiae

ibrutinib [2-4, 10, 12-14]; less common skin adverse events include purpuric painful nodules and pyoderma gangrenosum $[15,16]$. Hair changes associated with the use of ibrutinib include straightening and softening; increased curliness has also been reported [13].

Earlier studies reported by Farooqui et al. [10] and Bitar et al. [13] have noted nail changes associated with the use of ibrutinib. Farooqui et al. [10] described 51 patients with chronic lymphocytic leukemia treated with ibrutinib. In total, $22(43 \%)$ of the patients developed nail ridging.

Bitar et al. [13] described 66 patients with chronic lymphocytic leukemia treated with ibrutinib. Brittle fingernails were noted in $44(67 \%)$ patients, and toenail changes were observed in $15(23 \%)$ patients. The median time for onset of changes after initiating treatment with ibrutinib was 6.5 months for fingernails and 9 months for toenails. As with these individuals, both of our patients showed nail plate abnormalities within 6 months of initiating therapy with ibrutinib. The nail plate abnormalities were not a drug-limiting toxicity for any of these patients.

The pathogenesis of ibrutinib-induced nail changes has been postulated [13]. The integrity of the keratin-associated fibrous proteins is preserved by disulfide bonds between cysteine residues $[13,17,18]$. Ibrutinib covalently binds to the cysteine moieties near the active site of the tyrosine kinase enzyme [2, 4, 13]. Since cysteines are crucial for nail integrity, it is speculated that ibrutinib disrupts the disulfide bonds between the cysteine residues, causing nail brittleness to develop [13].

Fingernails typically grow $3 \mathrm{~mm}$ per month and toenails grow $1 \mathrm{~mm}$ per month. Therefore, the complete growth cycle is 3-6 months for fingernails and 12-18 months for toenails [13]. Hence, the appearance of ibrutinib-associated nail changes may not be noted until the nail has completed its growth cycle.

In most patients, treatment of the ibrutinib-induced nail brittleness or other drug-associated nail changes is not necessary. We recommended that our patients keep their nails short. We also prescribed daily biotin and recommended that the patients apply nail polish once a week. One of our patients noted significant improvement of her nails at follow-up examination 3 months after starting daily biotin.

\section{Conclusion}

Ibrutinib is used to treat chronic lymphocytic leukemia. It is usually well tolerated. Bruising, hair changes, nail plate abnormalities, pruritus and rashes are the most common cutaneous adverse events caused by ibrutinib. Similar to the individuals described in this report, many patients treated with ibrutinib develop nail plate abnormalities. However, this adverse event is not a drug-limiting toxicity.

\section{Compliance with Ethical Standards}

Funding No funding or sponsorship was received for this study or publication of this article.

Authorship All named authors meet the International Committee of Medical Journal Editors (ICMJE) criteria for authorship for this manuscript, take responsibility for the integrity of the work as a whole, and have given final approval for the version to be published.

Conflict of interest Lucas A. Heldt Manica, BS, and Philip R. Cohen, MD, have nothing to disclose. 
Informed consent Informed consent was obtained from the patients for being included in the study.

Open Access This article is distributed under the terms of the Creative Commons Attribution-NonCommercial 4.0 International License (http://creativecommons.org/licenses/by-nc/4.0/), which permits any noncommercial use, distribution, and reproduction in any medium, provided you give appropriate credit to the original author(s) and the source, provide a link to the Creative Commons license, and indicate if changes were made.

\section{References}

1. Vitale C, Griggio V, Todaro M, Salvetti C, Boccadoro M, Coscia M. Magic pills: new oral drugs to treat chronic lymphocytic leukemia. Expert Opin on Pharmacother. 2017;18:411-25.

2. Wiestner A. The role of B-cell receptor inhibitors in the treatment of patients with chronic lymphocytic leukemia. Haematologica. 2015;100:1495-507.

3. Lee C, Rattu M, Kim S. A review of a novel, Bruton's tyrosine kinase inhibitor, ibrutinib. J Oncol Pharm Pract. 2014;22:92-104.

4. IMBRUVICA ${ }^{\circledR}$ (ibrutinib) Dosing and administration for CLL I HCP. Imbruvicahcpcom. 2017. Available at: https://www. imbruvica.com/docs/librariesprovider7/default-document-library/ prescribing_information.pdf. Accessed August 4, 2017.

5. Mauro FR, Salaroli A, Caputo MD, Colafigli G, Petrucci L, Campanelli M, Ferretti A, Guarini AR, Foà R. Management of elderly and unfit patients with chronic lymphocytic leukemia. Expert Rev Hematol. 2016;9:1165-75.

6. Robak T, Stilgenbauer S, Tedeschi A. Front-line treatment of CLL in the era of novel agents. Cancer Treat Rev. 2017;53:70-8.

7. Rowswell-Turner R, Barr P. Treatment of chronic lymphocytic leukemia in older adults. J Geriatr Oncol. 2017;8:315-319.

8. Parikh S, Shanafelt T. Prognostic factors and risk stratification in chronic lymphocytic leukemia. Semin Oncol. 2016;43:233-40.

9. Ghia P, Hallek M. Management of chronic lymphocytic leukemia. Haematologica. 2014;99:965-72.
10. Farooqui MZ, Valdez J, Martyr S, Aue G, Saba N, Niemann CU, Herman SE, Tian X, Marti G, Soto S, Hughes TE, Jones J, Lipsky A, Pittaluga S, Stetler-Stevenson M, Yuan C, Lee YS, Pedersen LB, Geisler CH, Calvo KR, Arthur DC, Maric I, Childs R, Young NS, Wiestner A. Ibrutinib for previously untreated and relapsed or refractory chronic lymphocytic leukaemia with TP53 aberrations: a phase 2, single-arm trial. Lancet Oncol. 2015;16:169-76.

11. Gozzetti A, Defina M, Fabbri A. Myelosuppression after frontline fludarabine, cyclophosphamide, and rituximab in patients with chronic lymphocytic leukemia: analysis of persistent and newonset cytopenia. Cancer. 2013;120:451-2.

12 Byrd JC, Furman RR, Coutre SE, Burger JA, Blum KA, Coleman M, Wierda WG, Jones JA, Zhao W, Heerema NA, Johnson AJ, Shaw Y, Bilotti E, Zhou C, James DF, O'Brien S. Three-year follow-up of treatment-naive and previously treated patients with CLL and SLL receiving single-agent ibrutinib. Blood. 2015;125:2497-506.

13 Bitar C, Farooqui MZ, Valdez J, Saba NS, Soto S, Bray A, Marti G, Wiestner A, Cowen EW. Hair and nail changes during longterm therapy with ibrutinib for chronic lymphocytic leukemia. JAMA Dermatol. 2016;152:698.

14 Mannis G, Wu D, Dea T, Mauro T, Hsu G. Ibrutinib rash in a patient with $17 \mathrm{p}$ del chronic lymphocytic leukemia. Am J Hematol. 2014;90:179.

15 Mulvey J, Nuovo G, Magro C. Cutaneous, purpuric painful nodules upon addition of ibrutinib to RCVP therapy in a CLL patient. Am J Dermatopathol. 2016;38:492-8.

16 Sławińska M, Barańska-Rybak W, Sobjanek M, Wilkowska A, Mital A, Nowicki R. Ibrutinib-induced pyoderma gangrenosum. Pol Arch Med Wewn. 2016;126:710-1.

17 van de Kerkhof PC, Pasch MC, Scher RK, Kerscher M, Gieler U, Haneke E, Fleckman P. Brittle nail syndrome: a pathogenesisbased approach with a proposed grading system. J Am Acad Dermatol. 2005;53:644-51.

18 Cashman M, Sloan S. Nutrition and nail disease. Clin Dermatol. 2010;28:420-5. 